\title{
Study on Fujian Wood Carving Art
}

\author{
Haiming Jin ${ }^{1,2}$, Shanshan Jiang ${ }^{1, *}$ and Yilei Chen ${ }^{3}$ \\ ${ }^{1}$ Jiaxing Nanhu University, Jiaxing China; \\ ${ }^{2}$ Jiaxing University, Jiaxing, China; \\ ${ }^{3}$ Huzhou University, Huzhou, China \\ *Corresponding author.Email: 280175873@qq.com
}

\begin{abstract}
Fujian wood carving art is one of the important schools of Chinese wood carving,and deconstructing its artistic characteristics has important theoretical and practical value. Through the methods of literature review and field investigation, the history of Fujian wood carving art's development was combed, and the artistic features of Fujian wood carving were analyzed from the perspectives of geography, materials, technology and modeling. Then the artistic characteristics were extracted such as the beauty of charm, material and skill. The current statuses of Fujian wood carving art's development were summarized, and the challenges and problems that it's facing were analyzed. Finally, some ideas and suggestions were put forward for the sustainable and innovative development of Fujian wood carving art.
\end{abstract}

Keywords: Longan Wood Carving, Fuzhou Wood Carving, Putian Wood Carving, Quanzhou Wood Carving, Carving Art.

\section{INTRODUCTION}

Fujian wood carving has a long history, dating back to 1978 , when a turtle wooden plate of Shang and Zhou Dynasties 3000 years ago was unearthed in the white rock hanging coffin of Mount Wuyi. The shape is vivid and the wood carving techniques are simple. It is generally believed that Fujian wood carving originated from the architectural wood carving in Tang Dynasty, mature in the furniture and Buddha wood carving in Song Dynasty, and prosperous in the whole category of wood carving in Ming and Qing Dynasties According to different regions, Fujian wood carving can be generally divided into Fuzhou wood carving, Putian wood carving and Quanzhou wood carving; According to different techniques, Fujian wood carving can be generally divided into Longan wood carving, yellow poplar wood carving, golden lacquer wood carving, painted lacquer wood carving and so on.

Fujian wood carving art comes from life which makes it full of the breath of daily life. Due to the continuous development of technology and society, people's way of life is constantly changing. The development of Fujian wood carving art, such as Longan wood carving, Boxwood carving, golden lacquer carving and root carving, faces many challenges. It is of good research value to investigate and analyze the predicament of the development of Fujian wood carving art and put forward ideas and suggestions for sustainable development.

\section{THE DEVELOPMENT OF FUJIAN WOOD CARVING}

Fujian locates in the southeast coast of China, facing the sea and surrounded by mountains and hills, with valleys interwoven in between. The temperature is warm, the precipitation is sufficient, and the forest resources are rich [1].

Fujian culture also presents compatibility characteristics, including local Min and Yue culture before Qin and Han Dynasties, Han culture in central China since Jin Dynasty and Southern and Northern Dynasties, and overseas cultures from Southeast Asia, Africa and Europe brought by the Maritime Silk Road since Tang Dynasty. Fujian has a multi-ethnic population, with the largest Han population, including many ethnic minorities as well, such as She, Hui, Zhuang, Manchu, Miao, Mongolian and Tujia, form a cultural atmosphere in which Central Plains culture and minority culture coexist. Religious belief manifests itself in diversity and openness, including Mazu Madam Linshui, Qingshui the Founder, Life Protection Emperor, King Qingshan, King Guo and so on. In 
Fujian, deities of different religions can be worshipped. They live in harmony and share the incense of different religions. It has formed the cross-fusion of different regional cultures in China, the collision and integration of Chinese and foreign cultures and other characteristics of Fujian culture, which provides rich themes and creation carrier for Fujian wood carving art.

Fujian Longan wood carving, named for longan wood carving material, and Dongyang wood carving,Boxwood carving, golden lacquer wood carving are known as China's four schools of wood carving. Longan wood, commonly known as Guiyuan wood, is brown, with solid material and fine grain soft color, especially longan root, with root nodules scars, posture plenty, especially suitable for three-dimensional carving art.

Fuzhou Longan wood carving can be divided into three technical schools: Osaka school represented by Chen, Tianci, Xiangyuan school represented by Ke, Qingyuan, and Yanta school represented by Wang, Qingqing. Putian Wood carving is characterized by Buddhist modeling. Fang, Wentao, a Chinese arts and crafts master, is good at figure modeling and large Buddha sculpture. And another master Li, Fengrong has created a series of high-quality Buddhist wood carving works based on precious wood and integrating Putian traditional wood carving skills, which has achieved a new breakthrough in tradition. Hui'an wood carving, with plain Central Plains wood carving style, integration of delicate southern culture, formed the artistic characteristics of wood carving in southern Fujian.

Golden lacquer wood carving, using techniques of chopping, cutting and carving, with relief through carving, round carving and other forms of gold foil technology combined, not only achieves anti-corrosion protection, but also presents a resplendent visual effect. Golden lacquer wood carving is usually used in screen furniture, architectural decoration and furniture decoration, such as folding screen accessories of Laozi Depart Picture, architectural decoration pieces of Three Visits to the Hut Picture and furniture decoration pieces of Over the Wall Picture collected by Museum of Fujian.

\section{THE ARTISTIC FEATURES OF FUJIAN WOOD CARVING}

\subsection{Longan Wood Carving}

Fujian Longan wood carving art originates from life. With the improvement of living conditions and the increase of people's aesthetic needs and requirements, wood carving art has been integrated into all aspects of folk life in Fujian. People in Fujian have strong senses of family and often build ancestral halls to worship their common ancestors together during festivals. Ancestral temple is a place where the descendants of the same clan gather together and show the glory of the family, so the beams, columns, doors, windows and other architectural components in ancestral temple,commonly used relief through carving and round carving and other techniques for wood carving decoration,reflects the family's prosperous and glorious history. Ancestral temple building is decorated with exquisite wood carvings, presenting simply elegantly and colorfully. The same is true of temple architecture.

Fujian Longan wood carving is mainly used in architectural furniture and figures (Buddha) and other fields. Architectural carving is applied to the beams, columns, doors, windows, brackets, eaves, plaques and other structural and decorative components in ancestral halls and temples. Furniture carving is applied to screen, bed, cabinet, table, chair, bench and almost all wooden furniture. Buddhist sculpture is applied to the Mazu, Buddhism, Taoism, Christianity, Islam and Gods of different religions and various folk figures.

Fujian Longan wood carving is characterized by three-dimensional round carving and subtle-and-thorough carving, with rich and varied themes, including Guanyin, Arhat of Buddhism, Laozi of Taoism and Islam religious subjects, folk stories, myths and legends, people, animals, plants, landscapes, clouds, Tao Tie design, fret, Guai $\mathrm{Zi}$ pattern and so on. Wood carving art reflects people's yearning for better lives, the sustenance of spiritual belief and the inheritance of traditional etiquette.

\subsubsection{Fuzhou Wood Carving}

Fuzhou Osaka School, to figure carving and animal carving, the subject matter of creation is usually Maitreya, Guanyin, Ladies and all kinds of animals. The wood carving works are bold in style, beauteous in appearance and spirit, rich in expression, diversed in details, and vivid in shape. Representative figures are Beauteous Chen, Tianci, Chen, Yimei, Lin, Hengyun and so on.

Fuzhou Elephant Garden school wood carving uses flowers, birds, insects, fish, and auspicious animals as the theme of creation. The idea is clever, the modelling is concise, and the wit is full of life. Representative figures have $\mathrm{Ke}$, Qingyuan, Lin, Xueshan, Pan, Faqing and so on [2]. Among them, Lin, Xueshan's master work Hardship and Entrepreneurship, is as shown in Figure 1. 


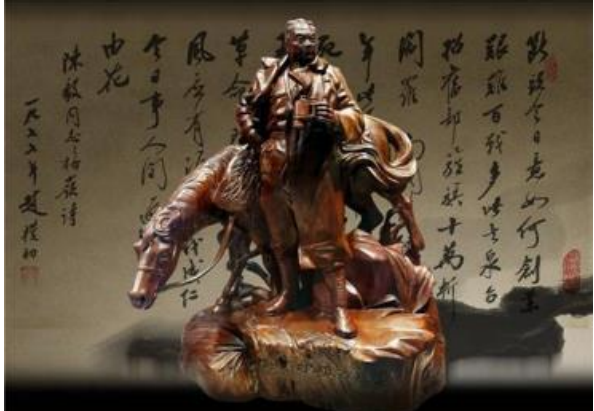

Figure 1, Hardship and Entrepreneurship, Lin, Xueshan

Fuzhou Yanta school wood carving, with patterns as the carving theme, generally combines with lacquer, using relief and carving techniques, has beautiful composition, sharp knife skills, vivid expression, and realistic shape. Representative figures are such as Chen, Longxiang, Chen, Dehe, Huang, and Senkang and so on.

\subsubsection{Putian Wood Carving}

Putian wood carving, developed from Longan wood carving, integrates with architectural art, takes figures (Buddha statues) as the main theme, takes fine and subtle carving as the artistic feature, selects precious wood as raw materials and applies modern aesthetic concepts to create a batch of fine wood carving. Representative figures are She, Guoping, Fang, Wentao and Li, Fengrong [3]. Among them, Li, Fengrong's master work Guanyin with nine lotus stands, is as shown in Figure 2.

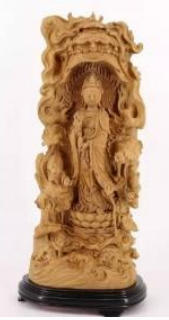

Figure 2. Guanyin with nine lotus stands, Li, Fengrong

Xianyou wood carving is an important part of Putian wood carving. It is ingenious in conception, rich in details, should be like the image and vivid. Rich themes include figures, animals, plants, landscapes, geometric patterns, auspicious patterns and so on, telling about traditional culture and presenting traditional art through legends, myths and stories. Relief through carving, round carving, hollow carving and other wood carving techniques are combined together, with superb skills, the wood carving art of traditional furniture has formed the characteristic and brand of "fairy works".

\subsubsection{Quanzhou Wood Carving}

It is generally believed that Quanzhou wood carving includes Quanzhou city, Xidi of Hui'an and Panshan of
Jinjiang, etc. It is mainly used in temples, folk buildings, Buddha statues, puppets and other fields. The rise of Quanzhou wood carving is closely linked with the development of Buddhism, taking the example of the wood carving decorative components of Kaiyuan Temple, and the Thousand-handed Guanyin of Longshan Temple in Anhai of Jinjiang.

Quanzhou wood carving, in architectural wood carving decoration, uses line carving, round carving, relief transparent carving and other techniques in beams and columns, brackets, doors and windows, and other positions. Artistic aesthetics lead to the extreme. Puppet head carving is another important field of Quanzhou wood carving, life-like, and it also has a large number of applications in the puppet show. Buddha sculpture, uses three-dimensional round carving techniques. The facial expression is delicate, vivid, and wrinkle fluttering. The main themes are Eighteen Arhats, Maitreya, Guanyin and Bodhidharm. Famous sculptors include $\mathrm{Xu}$, Lou, Huang, Liang, Huang, Cai, Yao, Songlin, Zhan, Zhenhui, Lian, Honggou, Zhu Fu, and so on [4].

\subsection{Artistic Characteristics}

\subsubsection{The Beauty of Artistic Conception}

Fujian is a gathering of talents city, nourished a large number of literati. In particular, painting and calligraphy artists have actively promoted the development of woodcarving art. For example, Fujian calligraphers and painters since Song Dynasty include Zhu, Xi, Cai, Xiang, Chen, Rong, Zheng, Sixiao, Zhang, Ruitu, Bian, Jingzhao, Wu, Bin, Huang, Daozhou, Wang, Jianzhang, Yi, Bingshou, Zhang, Shen and Lin, Zexu. The wood carving artist applies the scatter perspective technique in Chinese painting to the large area of relief wood carving art, People near and far and different scenes are skillfully organized in one frame. All the objects in the wood carving work are well arranged, constructing a beautiful picture with clear hierarchy and harmonious unity.

Masters of calligraphy and painting all have the cultivation of traditional Chinese culture, blending the spirit of Confucianism, Buddhism and Taoism into the art of calligraphy and painting. When wood carvers apply Chinese painting and calligraphy composition techniques, they naturally integrate traditional culture such as Confucianism, Buddhism and Taoism into their wood carvings. The basic idea of Confucianism is "respect", emphasizing the Literature and Quality. When the Quality wins the Literatue, it would lead to wild, and when the literature wins the Quality, it would lead to history. The ornamental and the combined plain properties, and then a gentleman requires the organic unity of content and form. Spirit of Taoism is that human follows land, land follows sky, and sky follows Taoism, Taoism follows nature. And the thought of 
"quiet" based on the unity of nature and man. Aesthetics emphasizes that Tao, air and image cannot be separated. The basic idea of Buddhist is "clean", attaching importance to the beauty of artistic conception, and the image of the outside, the meaning of the accident. In short, the thought of Confucianism, Buddhism and Taoism is reflected in Fujian wood carvings, it shows wood carving art's the beauty of artistic conception.

\subsubsection{The Beauty of Material}

Fujian wood carving uses local materials. The common materials are longan wood, camphor wood, Chinese fir, and boxwood. But also, it can choose chicken wing wood, nanmu, rosewood, tieli wood, red acid branches and other foreign wood. Each wood has its own unique texture color and mechanical properties. Wood carvers, according to the wood of the material, design ideas, using suitable wood carving techniques, carving compositions clever, unique shapes, beautiful textures, exquisite techniques of wood carving art works. In the wood carving works, different forms of hardness, texture and color of the material between the coordination and complement each other, fully reflect the wood carving art's material beauty.

\subsubsection{The Beauty of Technology}

Fujian wood carving uses chopping carving skills, flat knife block surface method and round knife carving method, through line carving, relief carving, transparent carving, hollow carving, round carving and other carving techniques, various forms are presented, according to the characters of the materials. Fujian wood carving gives smooth lines, vivid images, exquisite techniques and other skills, and at the same time, in the art of wood carving, other techniques such as painting, mosaic, and splicing are also used, presenting an art aesthetic scene with a variety of technologies, a variety of skills complement each other.

\section{DEVELOPMENT DILEMMA AND INHERITANCE SUGGESTIONS OF FUJIAN WOOD CARVING}

Due to social development and changes in people's needs, the development of Fujian wood carving is facing a series of problems and difficulties [5], which is just like other traditional skills. According to the investigation and analysis, this paper puts forward the ideas and suggestions to get rid of difficulties, which are mainly summarized in three aspects below.

\subsection{The Existing Training Mode Cannot Meet the Needs of Inheritance, So It Is Necessary To Build A New Talent Training Mechanism}

Fujian wood carving talent cultivation adopts the traditional mentoring mode of apprenticeship system, which is taught orally and personally. Even the unique wood carving skills become ancestral secrets and are only passed on to disciples with blood relationship. It is difficult for outsiders to inherit their core skills, and it is impossible to carry forward their characteristic skills.

Based on the traditional cultivation of mentors, the government and industry associations establish relevant evaluation mechanisms and incentive measures, update the concept of wood carving art and craft masters and make them willing to contribute ancestral secrets, so as to cultivate more excellent inheritors.

\subsection{The Creative Ideas of Wood Carving Works Are Old, So It Is Necessary to Cultivate the Cross-border Thinking of Wood Carving Creation}

Fujian wood carving art creation method is traditional. Carving art works are often concentrated in a certain direction of tradition, lacking innovation. Therefore, wood carving works cannot meet the actual needs of modern life. Wood carving artists usually focus on their own fields only, owning low educational background, single knowledge structure and narrow creative ideas.

Fujian wood carving artists should jump out of their narrow field, actively learn and communicate with relevant personnel in the fields of design, creativity and art, in order to realize cross-border collision of thinking, explore new creative ideas, and create new wood carving works to meet people's needs for wood carving art in the new era. For example, you can participate in the training course for inheritors of China's intangible cultural heritage sponsored by the Ministry of Culture and the Ministry of Education. During the learning process, the trainees can conduct all-round discussions and exchanges on artistic aesthetics, design methods and creative thinking with experts and masters in different fields such as well-known professors in Colleges and universities and arts and crafts masters, so as to expand creative ideas and cultivate cross-border thinking.

\subsection{The Wood Carving Category Is Not Rich and the Business Model Lags Behind, So It Is Necessary to Expand the Wood Carving Category and Build A New Operation Model}

The traditional wood carving brand concept is not new, and the market lacks well-known wood carving brands. 
With the help of mobile internet and other information technologies, it creates more personalized and customized wood carving works and enriches the categories of wood carving works to meet the aesthetic needs of modern people, on the basis of traditional carving art types. At the same time, we can build a business model based on mobile internet, expand sales channels, and initially build a new operation model of wood carving art, which is based on the traditional market model.

\section{CONCLUSION}

Fujian has a long history. Its unique and harmonious geographical environment, distinctive characteristics of folk lifestyles and multi-cultural compatibility has nourished Fujian wood carving art with obvious artistic characteristics and cultural values. Fujian wood carving art is an important part of Chinese wood carving art. It contains traditional artistic values such as subject selection, composition form, wood carving techniques and craftsman spirit. It is an important source for the inheritance and development of Chinese traditional art and culture, which needs our continuous research, exploration and practice. Due to the rapid development and changes of people's lifestyle, social environment and modern technology, the sustainable development of Fujian wood carving art has encountered a series of problems and challenges. The innovative development of Fujian wood carving needs careful study and judgment, combined with the continuous upgrading of demand, and integrating the development trends of cultural industry and creative industry. Fujian wood carving will explore new guiding theories and continuously practice and iterative upgrading.

\section{ACKNOWLEDGMENTS}

This paper is supported by MOE (Ministry of Education in China) Youth Project of Humanities and Social Sciences (Project No. 17YJC760028)

\section{REFERENCES}

[1] Liao, Shangang. Fujian Geography [M]. Beijing: Beijing Normal University Press, 2018

[2] Zhong, Yao. Analysis on the current situation and development of wood carving in Fuzhou elephant Garden [J]. Art literature. 2020, (05): 149-150

[3] Li, Chaoyang. Inheritance and innovation of Putian wood carving [J]. Popular color, 2020, (06): 89-90

[4] $\mathrm{Wu}$, Zhihao. Research on inheritance, innovation and development of Quanzhou wood carving [J]. Masterpieces. 2020, (02): 114

[5] Meng, Weidong. Study on the value and Protection Countermeasures of traditional carving culture in Fujian Province [J]. Creativity and design. 2019, (04): 55-60 